\title{
Urethral duplication II-A Y type with rectal urethra: ASTRA approach and tunica vaginalis flap for first stage repair
}

Antonio Macedo Jr, Atila Rondon, Herick Bacelar, Sergio Ottoni, Riberto Liguori, Gilmar Garrone, Valdemar Ortiz

Department of Urology, Universidade Federal de São Paulo, UNIFESP, São Paulo, Brazil

\section{ABSTRACT}

Introduction: Urethral duplication is a rare congenital anomaly affecting mainly boys. Generally, the duplication develops on the sagittal plane; the accessory urethra may run dorsally or ventrally to the orthotopic one. We present a patient with urethral duplication in which the orthotopic urethra was patent in the penile segment but atresic in the bulbar and prostatic segment. The patient had urinary flow from the rectum and the ectopic urethra could be well identified by anal examination. Materials and Methods: Age at surgery was 13 months. The procedure consisted of an ASTRA (anterior sagittal trans-ano-rectal) approach for dividing the urethra and rectum and was successful to move the urethra up to the perineal area. The rectum was reconstructed and the patient placed into a lithotomy position. A urethral catheter inserted in the penile urethra oriented us were the atresic urethra in bulbar area started. The scrotum was opened in the middle and the distance between the two urethral stumps proximal and distal defined the extension of no urethral tissue that consisted of $5 \mathrm{~cm}$. We opened the right scrotal space and a tunica vaginalis flap was obtained and attached to the bulbar tissue for a two-stage urethroplasty strategy. Results: Patient had a nice healing and the tunica vaginalis was nicely incorporated to the adjacent tissue, having the two urethral stumps well delineated.

Conclusions: ASTRA approach in combination with a two-stage urethroplasty with tunica vaginalis dorsal flap proved to be an excellent combination for a rare case of urethral Y duplication having the main urethra into the rectum.

\section{ARTICLE INFO}

Available at: www.brazjurol.com.br/videos/september_october_2012/macedo_707_708video.htm

Int Braz J Urol. 2012; 38 (Video \#6): 707_708

Submitted for publication:

July 26, 2012

Accepted after revision:

September 15, 2012
Correspondence address: Dr. Antonio Macedo Jr. Rua Maestro Cardim, 560 / 215 São Paulo, SP, 01323-000, Brazil Fax: + 5511 3287-3954

E-mail: macedo.dcir@epm.br 


\section{EDITORIAL COMMENT}

Macedo et al. present a video that nicely demonstrates the first stage of a planned twostage procedure. Urethral duplication are rare congenital anomalies. The urethral configurations and patient symptomatology can vary greatly. Patients can be completely asymptomatic. They can have two parallel urinary streams or, as in this case, can present with rectal urinary incontinence (1). The anterior sagital trans-anorectal approach (ASTRA) was described by Di Benedetto and Di Benedetto for use in clitorovaginoplasty (2).

\section{REFERENCES}

1. Effmann EL, Lebowitz RL, Colodny AH: Duplication of the urethra. Radiology. 1976; 119: 179-85.

2. Di Benedetto V, Di Benedetto A: Introduction of the anterior sagittal trans-ano-rectal approach (ASTRA) as a technical variation of the Passerini-Glazel clitoro-vaginoplasty: preliminary results. Pediatr Med Chir. 1997; 19: 273-6.

3. Haleblian G, Kraklau D, Wilcox D, Duffy P, Ransley P, Mushtaq I:Y-type urethral duplication in the male. BJU Int. 2006; 97: 597-602.
Y-type duplications with a perineal or rectal urethral meatus are often accompanied by other congenital anomalies such as renal agenesis, cryptorchidism, anorectal malformations or sacral agenesis. They can also be the most challenging to repair, often requiring multiple surgeries (3). In general, the dorsally-positioned urethra is the accessory urethra. Single-stage repairs using buccal mucosa grafts as a free-tube have been reported (4).

We look forward to the authors' submission of the second-stage surgery for this child with an uncommon and challenging anomaly.

4. Mane SB, Obaidah A, Dhende NP, Arlikar J, Acharya H, Thakur $A$, et al.: Urethral duplication in children: our experience of eight cases. J Pediatr Urol. 2009; 5: 363-7.

Dr. Hubert Swana Pediatric Urology Nemours Children's Clinic Orlando, USA E-mail: hswana@nemours.org 